\title{
Curumim: A Robótica Educacional como Proposta Metodológica para o Ensino
}

\author{
Ana Cláudia Molina Zaqueu1, Daniel Costa Ramos², Antonio Valério Netto² \\ ${ }^{1}$ Programa de Pós-Graduação em Educação Matemática - Unesp, Campus de Rio Claro \\ - Rio Claro, SP - Brasil. \\ ${ }^{2,3}$ Xbot - São Carlos, SP - Brasil. \\ anaclaudiam.zaqueu@gmail.com, danielexbot.com.br, valerio@xbot.com.br
}

\begin{abstract}
In this article will be presented a methodological proposal which is based on the use of the educational robotics for teaching the programming language on a mechatronics technician course.For this, supported by the conceptions offered by Xbot,company focused on production and commercialization of mobile robots for entertainment and education,was developed a material facing the professor containing all the methodology that involves the use of the robot, in this case, the Curumim. Furthermore, the lecturers attended a qualification course wherein all the activities offered in the material were developed. We emphasize that this offer comes with an access for a portal (restricted) wherein professors (that participated in the course) can have access to the material,chats, among others things,providing an exchange of experience and favoring their formation.
\end{abstract}

Resumo. Neste artigo apresentaremos uma proposta metodológica a qual baseia-se no uso de robótica educacional para o ensino de linguagem de programação em um curso técnico de mecatrônica. Para isso, respaldados nas concepções propostas pela Xbot, empresa voltada à elaboração e comercialização de robôs móveis para as áreas de educação e entretenimento, foram desenvolvidos materiais voltados ao professor contendo toda a metodologia que envolve o uso do robô, neste caso, o Curumim. Além disso, os docentes participaram de um curso de capacitação em que todas as atividades propostas no material foram desenvolvidas. Destacamos que esta proposta conta com um portal (fechado) em que os professores (que participaram do curso) têm acesso aos materiais, chats, entre outras coisas, proporcionando uma troca de experiências e um espaço de formação.

\section{Introdução}

Ao observarmos a História da Educação no Brasil, torna-se perceptível o quanto o país tem buscado, via inúmeras reformas educacionais e políticas públicas, medidas (emergenciais ou não) capazes de suprir as necessidades formativas do país no âmbito da formação de professores e, consequentemente, qualidade do Ensino Básico, Superior e Técnico. Este olhar para a História da Educação de nosso país mostra-se relevante ao passo que possibilita compreender motivações e/ou mudanças ocorridas no âmbito da Educação no que refere-se à formação de professores e Educação de modo geral. Diante disso, podemos afirmar que a Robótica Educacional, mesmo não sendo uma 
realidade para a maioria dos estudantes, tem participado no processo de formação de alguns alunos da educação Básica, Superior e Técnico.

No Brasil, podemos afirmar que a Robótica Educacional passa a ser pensada a por volta de 1975 quando Seymour Papert e Marvin Minsky desenvolvem a fundamentação e conceitos da linguagem Logo. Segundo Curcio (2008), nos anos seguintes foram realizados estudos que envolviam crianças e a linguagem Logo. A partir disso, mesmo que em passos lentos, a Robótica Educacional tem buscado espaço na Educação de crianças, jovens e adultos, uma vez que Papert (2002), entende que as tecnologias podem participar do processo educacional.

Frente a isso, destacamos o fato de que, atualmente, vivemos em um tempo acelerado no qual inúmeras mudanças ocorrem em pequenos espaços deste tempo. Adaptar-se a este "novo" cenário é um desafio para nossa sociedade e também para o ensino de modo geral. Frente a tamanhas modificações, a escola, a formação e, principalmente, as práticas e metodologias adotadas, necessitam de mudanças para que possamos nos adaptar e acompanhar esta evolução natural.

As tecnologias estão cada vez mais presentes no cotidiano dos alunos, professores e sociedade em geral. Desse modo, elas podem ser caracterizadas como importantes dispositivos para a educação. Nas últimas décadas, muito se tem visto em pesquisas e no próprio discurso dos alunos e professores sobre a importância do computador, por exemplo, para o ensino em nível técnico, superior ou básico.

Assim, questões importantes podem ser mobilizadas, como por exemplo: Em que medida tais tecnologias não estão somente impregnadas no discurso acadêmico e de alunos, sem serem praticadas efetivamente? Até que ponto o uso dessa Tecnologia da Informação e Comunicação (TIC) tem de fato contribuído para a formação de um aluno com pensamento crítico capaz de tecer argumentações e agir conscientemente? Devemos ter ciência de que devido a estas mudanças na sociedade, o ensino deve ir ao encontro delas e, ao mesmo tempo, os professores precisam buscar articulações que agreguem em suas práticas pedagógicas meios que potencializem a formação de um aluno que busque conhecimento, compartilhe suas experiências e crie uma visão crítica do mundo que o cerca. Desse modo, corroboramos com Pierre Lévy (1998) ao afirmar que "todas as evoluções que se estão esboçando na área educacional estão em congruência com as modificações das atividades cognitivas observadas em outras áreas" (p.34).

Diante dessas inovações, alunos e professores tecem críticas uns aos outros, a fim de justificarem o modo como o ensino tem se estabelecido. Neste contexto, alunos afirmam que têm dificuldades no processo de ensino-aprendizagem devido ao fato de que o professor ministra aulas tradicionais, utilizando giz, lousa e aplicando listas de exercícios como fixação. Por outro lado, os professores argumentam pautados na ausência de tempo para sua formação continuada, no fato dos alunos estarem dispersos e desinteressados com o conteúdo, no uso de celulares durante a aula, entre outras coisas.

Assim, corroborando com Silva (2007) e frente a tais argumentos, mudanças tecnológicas e ainda, pensando nos questionamento levantados anteriormente, a empresa XBot, criada em 2007 na cidade de São Carlos, interior do estado de São Paulo, tem trabalhado com a fabricação e comercialização de robôs móveis para as áreas de educação, pesquisa e entretenimento, tendo por um de seus objetivos, desenvolver nos alunos habilidades distintas e possibilitar a troca de experiências. 


\section{O Pensar de uma Proposta Metodológica}

Atentos às necessidades de mudanças no processo de ensino-aprendizagem, na importância de articular educação e tecnologia e, pautados na teoria do conhecimento proposto por Seymour Papert, a empresa Xbot, volta sua atenção para a elaboração de uma proposta metodológica na qual articula os pensamentos de Papert com a Realidade Virtual (imersão, iteração e envolvimento).

Antes de explicarmos a proposta metodológica da Xbot, alguns pontos devem ser ressaltados como, por exemplo: Quem foi e o que pensava Seymour Papert? O que entendemos por Realidade Virtual? Como percebemos a tecnologia articulada com a proposta metodológica? Propomos efetivamente uma metodologia ou mais um recurso metodológico para o ensino? Entendemos que tais questionamentos ajudarão na compreensão de nossa proposta metodológica.

Seymour Papert, segundo Hiran Pinel (2004), foi um matemático nascido na África do Sul, considerado um dos pais no campo da inteligência artificial e reconhecido internacionalmente por defender as potencialidades do uso de tecnologias para (e na) educação. Papert se aproxima dos pensamentos de Jean Piaget ao afirmar que o sujeito é o principal formador de seu conhecimento. Em ambos os casos, o professor é visto como um sujeito capaz de proporcionar ao aluno um ambiente que favoreça o enriquecimento de seus conhecimentos; em outras palavras, o professor ocupa uma posição mais passiva, tornando-se um mediador, sendo sua função provocar e proporcionar aos alunos momentos que os levem a questionar-se sobre o conteúdo, criar estratégias, socializar e assim, ser o "agente" principal de seu conhecimento. Visto isso, assim como Pais (2002), entendemos que o aluno é, efetivamente, o construtor de seu conhecimento.

Além disso, a proposta de Papert, o construcionismo, muito se aproxima do construtivismo proposto por Piaget. Papert propõe que o aluno investigue situações, busque soluções, articule, pense e formule. Em meio a este processo, o professor estabelece uma mediação, buscando incentivar sempre o pensamento e não responder aos questionamentos de modo pronto e acabado. Seguindo esta perspectiva, a relação aluno-professor, aluno-aluno, passa a favorecer o ambiente de aprendizado e as trocas de experiências ocorrem de forma natural, potencializando a vivência de experiências tal como proposto por Larrosa (2002) e, além disso, o aluno se insere no ambiente, construindo seu conhecimento a partir da prática e não somente da teoria vista de modo tradicional.

Outro aspecto relevante da metodologia proposta pela Xbot está respaldado nos três segmentos da Realidade Virtual (RV) ou seja, imersão, interação e envolvimento. Segundo Netto, Machado e Oliveira (2002), a imersão está relacionada ao fato de fazer com que o aluno se sinta parte do ambiente no qual está inserido ou seja, faça parte dele; a interação consiste no fato do computador ou, no caso da metodologia da Xbot, o robô, ser capaz de modificar o mundo virtual a partir de ações do sujeito/aluno; já o envolvimento, está relacionado com o grau de motivação e engajamento do sujeito participante da ação, no caso o aluno. Sendo assim, estas ideias da RV vão ao encontro do que é proposto por Papert e mais do que isso, favorecem o processo de construção de conhecimento no qual Papert se insere. 
Com relação à tecnologia, a entendemos, nós da Xbot, como um dispositivo no qual, articulado com uma metodologia bem fundamentada, pode proporcionar o tão esperado ensino por meio de tecnologias, aproximando os professores dos alunos. Nesta proposta, a tecnologia não mais é vista como uma distração para os alunos nem algo distante para os professores. A tecnologia, neste caso, é peça fundamental para a construção do conhecimento.

Outro aspecto que muito incomoda é o fato de que se o que propomos é uma metodologia ou um recurso pedagógico. Frente a isso, ressaltamos que a proposta que apresentamos é de fato uma metodologia, uma vez que compreendemos metodologia como o estudo de métodos na qual traz explicações minuciosas e rigorosas de uma ação.

Desse modo, articulando as ideias explicitadas anteriormente propusemos uma metodologia na qual utilizamos a robótica educacional como estímulo para que os alunos possam vivenciar este ambiente, tomar para si os desafios nele colocado e por meio de relações, pensamentos e estratégias, construir seu conhecimento. Assim, corroboramos com Kozen (2007) ao afirmar que "a robótica educativa visa ao processo de construção e elaboração do pensamento do aluno. Na robótica educativa o caminho percorrido pelo aluno até a chegada a um determinado produto é a fase mais importante."

Por outro lado, temos ciência de que muitos professores possuem dificuldades em trabalhar com tecnologias em geral e por isso, preparamos uma estrutura detalhada desta metodologia na qual contempla desde elaboração de material (planos de aula PA) até curso de capacitação e apoio online via portal educacional.

Desse modo, nossa proposta metodológica percorre, rigorosamente, os seguintes procedimentos: ao requisitar a implantação da metodologia na instituição, são oferecidos os produtos educacionais da Xbot, o Curumim por exemplo, a equipe educacional da empresa realiza uma articulação para combinar o referencial teórico adotado pela instituição ao uso das funcionalidades do robô. A partir disso, são elaborados os planos de aula, as quais contém, necessariamente, todo o conteúdo previsto para a disciplina, atividades, os objetivos de cada atividade, as capacidades a serem desenvolvidas e uma sugestão para avaliação do aluno. Todos este material é entregue ao professor em forma de apostila e vídeo aula. Entretanto, cientes daquelas dificuldades já citadas, é oferecido aos professores um curso de capacitação, presencial, no qual a maioria das atividades propostas na apostila são desenvolvidas com eles (professores) para que, ao aplicarem em suas salas de aulas, sintam-se motivados e seguros para trabalharem com seus alunos.

Cabe ressaltar que estes cursos de capacitação contam com, no máximo, quatorze professores a serem escolhidos pela instituição e estes são responsáveis por levar o conteúdo até os demais ou seja, serão os "replicadores" da metodologia. Além disso, estes professores têm livre acesso ao portal educacional criado pela Xbot na qual fica disponibilizado vídeo aulas, materiais de apoio e é possível a troca de mensagens entre os professores e a equipe de acompanhamento educacional. Lembrando que esta equipe é disponibilizada, exclusivamente, para atender as dúvidas desses professores. 
Assim, entendemos que esta proposta metodológica proporciona ao aluno um ambiente no qual ele se sinta motivado a aprender e produzir seu conhecimento, tornando as aulas mais dinâmicas e atrativas. Já para o professor, todo o apoio lhe é oferecido de modo a suprir suas dificuldades tanto em termos de conteúdo, quanto aplicação e possibilita momentos de formação continuada que muitas vezes o são negados ou negligenciados.

A seguir, apresentaremos um exemplo desta metodologia desenvolvida para o ensino técnico em mecatrônica. A proposta a seguir foi desenvolvida a partir do kit Curumim.

\subsection{Curumim: Proposta Metodológica para o Ensino de Linguagem de Programação}

Neste tópico, apresentaremos uma proposta para o ensino de linguagem de programação para o ensino técnico em mecatrônica.

Uma das dificuldades do curso de linguagem de programação é a defasagem que os alunos possuem, muitas vezes, fruto de dificuldades na educação básica. $\mathrm{O}$ uso da lógica e a compreensão do problema são fundamentais na linguagem de programação. Para que o aluno consigo resolver determinados problemas propostos é preciso que ele compreenda o que se é pedido, pense logicamente e crie estratégias que possam fazer com ele atinja seus objetivos.

Pensando nisso, o uso do kit Curumim, Figura 1, proporciona este conjunto de "objetos" necessários para que o aluno construa seu conhecimento.
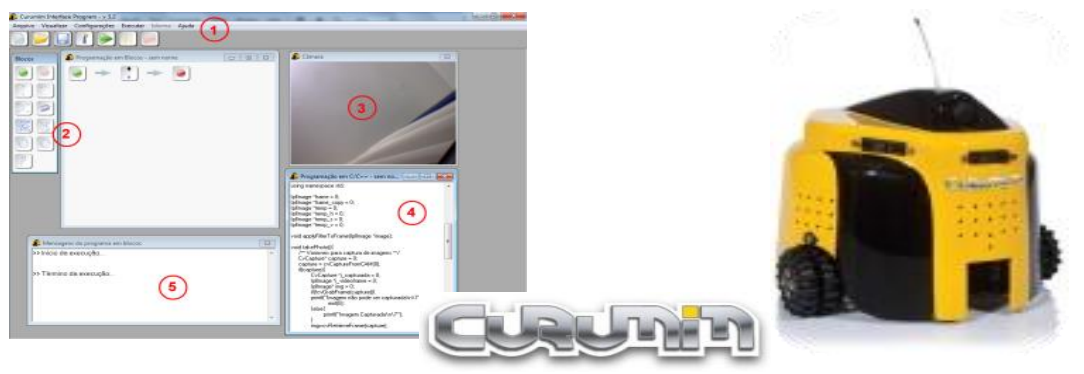

Figura 1. Kit Curumim.

As atividades propostas na apostila destinada a este curso, contempla os conteúdos de Introdução e Conceitos Básicos, Lógica de Programação, Instruções Condicionais, Instrução de Laço, Situações Problema, Programação Estruturada, Programação em $\mathrm{C} / \mathrm{C}++$, Instrução de Condicionais $(\mathrm{C} / \mathrm{C}++)$, Instrução de Laço $(\mathrm{C} / \mathrm{C}++)$, Situações Problemas $(\mathrm{C} / \mathrm{C}++)$ e um Desafio de Programação.

Cabe destacar que, ao elaborar este material, todos os pressupostos no qual acreditamos estão inseridos em cada atividade ou seja, ao propor cada atividade, temos por objetivo favorecer aspectos que façam com o aluno consiga sentir-se parte do ambiente no qual está vivenciando (imersão), seja capaz de através das relações interpessoais, conhecimentos prévios, articulação e criação de estratégias, efetuar ações 
no robô (interação) e sinta-se motivado a participar das atividades, aplicando as teorias já internalizadas (envolvimento).

Para melhor conhecimento do que seria esta metodologia baseada em robótica educacional, apresentaremos, a seguir, um exemplo de atividade proposta no material desenvolvido, via Kit Curumim, para o ensino de linguagem de programação em um curso técnico de mecatrônica. Lembramos que esta atividade seguiu os moldes da metodologia desenvolvida pela Xbot ou seja, antes de ser implementada em sala de aula com os alunos, os professores participaram do curso, tiveram conhecimento das atividades, de como poderiam explorá-las e também, tiveram (e tem) acesso ao portal educacional onde há materiais de apoio, vídeo aulas, entre outras coisas que já citamos.

O exemplo selecionado para este artigo refere-se a um plano de aula voltado para o ensino de lógica de programação.

No início do plano de aula, temos um quadro no qual consta informações tais como: o curso, Ensino Médio Técnico; a disciplina, Linguagem de Programação I; o professor responsável pela elaboração, neste caso, Daniel C. Ramos; o tempo estimado para o desenvolvimento da mesma, quatro aulas de cinquenta minutos; o subtema do PA, Lógica de programação e o link para o portal educacional, http://www.portal.xbot.com.br. Estes itens, assim como as informações que fazem parte dos planos de aula, são padronizadas ou seja, todas, obrigatoriamente, contém estes dados.
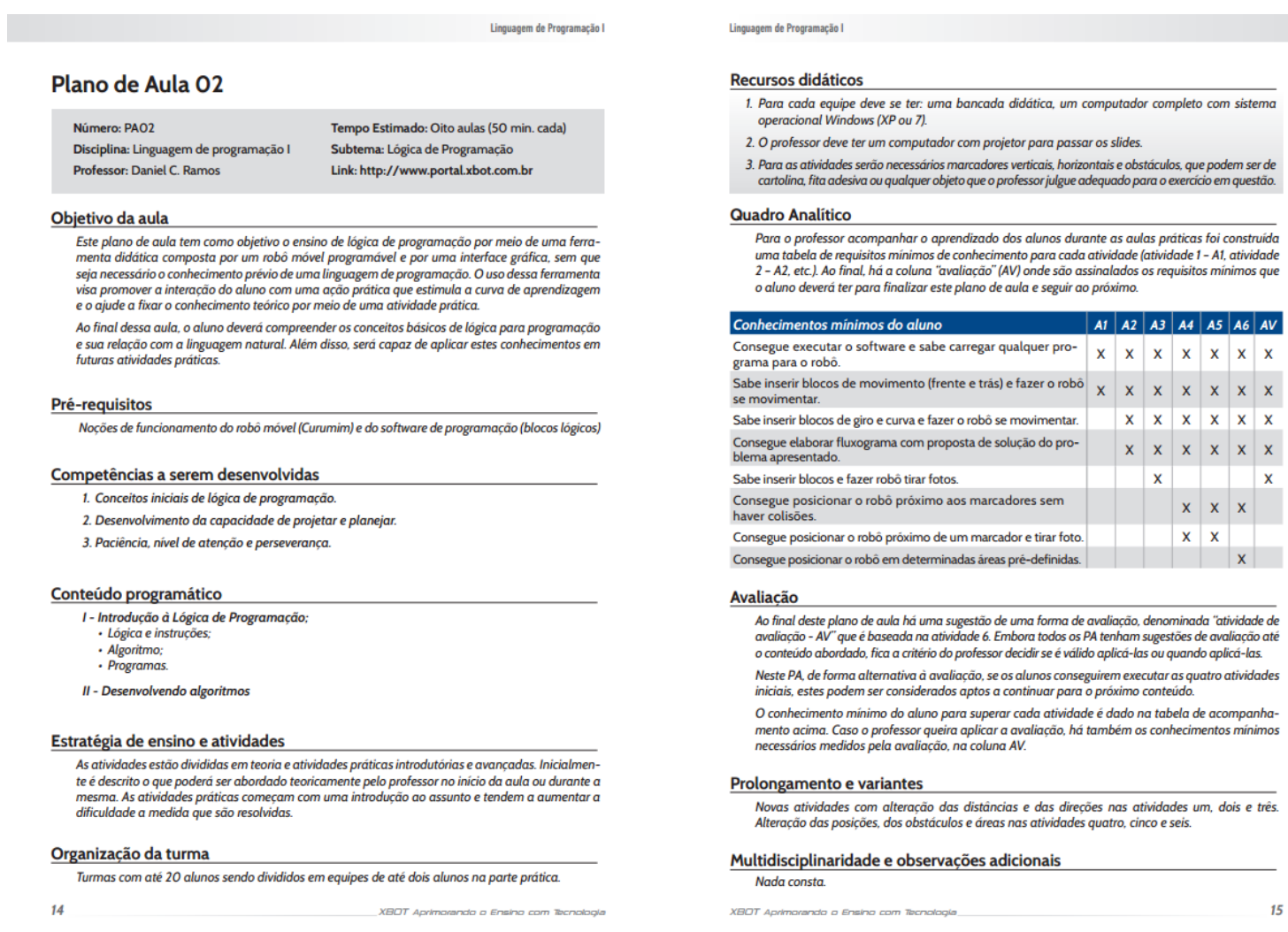

Figura 2. Exemplo de início de plano de aula. 
Logo abaixo, encontra-se um quadro de informações com o objetivo geral do PA que, no caso deste exemplo, visava o ensino de lógica de programação utilizando um robô móvel programável, Curumim, e uma interface gráfica sem que fosse necessário conhecimentos prévios de alguma linguagem de programação. Com isso, espera-se que os alunos interajam e, via prática, compreendam os conceitos básicos de lógica e sua relação com a linguagem natural. Além disso, o professor encontra neste material quais os pré-requisitos para a aplicação dos PAs e as competências a serem desenvolvidas. Neste exemplo, os alunos deveriam ter noções sobre o funcionamento do Curumim, do software de programação que o acompanha (blocos lógicos) e ainda, as competências a serem desenvolvidas seriam: os conceitos iniciais de lógica de programação, desenvolvimento da capacidade de projetar e planejar e atenção. Ainda com relação às informações iniciais, o professor encontra listados todo o conteúdos programático do PA, sugestões de como organizar a sala de aula, alunos e avaliar.

Feitas as devidas considerações gerais, válidas para todas as atividades contidas no plano de aula, incluindo a atividade de avaliação (AV), são apresentadas, detalhadamente, cada atividade.

$\mathrm{Na}$ primeira atividade denominada "primeiros passos", os alunos deveriam explorar o kit Curumim, buscar compreender o funcionamento do robô e a relação com a programação que desenvolviam no software e no final da aula, serem capazes de movimentar o robô. Notem que já nesta atividade, os conceitos da RV são muito presentes. No final desta atividade, assim como nas demais, existe um quadro com sugestões para atividade de recuperação caso algum aluno tenha tido dificuldades para acompanhar e desenvolver as atividades propostas.

Na atividade dois, "um problema de direção", os alunos deveriam organizar-se, pensar logicamente e criar estratégias para resolução dos primeiros problemas por meio da formulação de algoritmos em linguagem natural. Nesta atividade, o professor pode direcionar os alunos pedindo que façam com que o robô caminhe em uma direção e depois mude seu percurso.

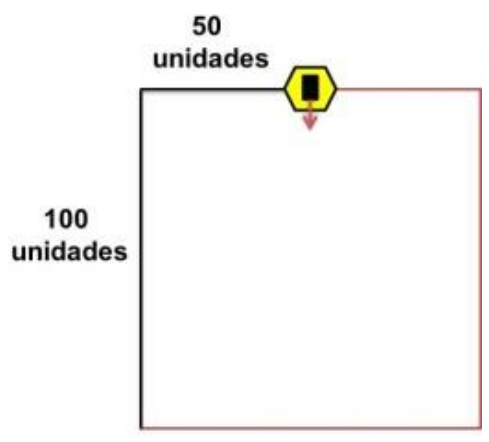

Figura 3 - Atividade 2 do plano de aula exemplo.

Já na atividade três, "movimentos e fotos", os alunos deveriam explorar todos os recursos oferecidos pelo Kit. Apesar de ser uma atividade similar à anterior, ao impor o uso dos demais recursos do robô, o nível de dificuldade torna-se maior uma vez que impõe ao aluno a necessidade de elaboração de novos meios para que execute a tarefa com sucesso. 
A atividade quatro, "marcadores", os alunos deveriam montar um fluxograma, sem auxílio do professor, construir um algoritmo para o robô de forma a solucionar o seguinte problema: dada posição inicial do robô, deseja-se tirar fotos de dois objetos. Ou seja, tirar uma foto de um marcador com o robô em uma posição/orientação e depois uma foto de outro marcador com o robô em uma outra posição/orientação.

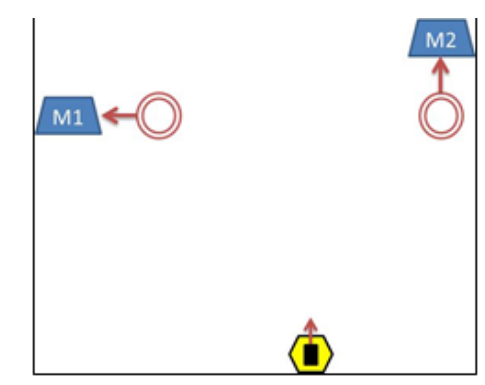

Figura 4. Atividade 4 do plano de aula exemplo.

Na atividade cinco, "obstáculo", os alunos devem fazer com que o robô desvie de obstáculo, caso existissem. Nesta atividade, as ideias de instruções condicionais aparecem de modo natural ao aluno.

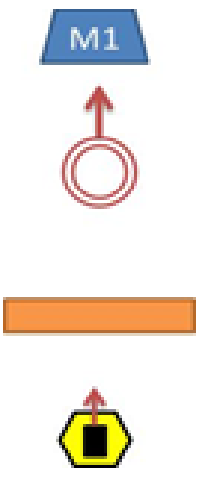

Figura 5. Atividade 5 do plano de aula exemplo.

$\mathrm{Na}$ atividade seis, "sequência de posições", os alunos devem criar estratégias para que o robô percorra trajeto entre as regiões demarcadas, a atividade se dá por encerrada no momento em que o robô pare na região demarcada. Nesta atividade, os conceitos de instrução de laço são introduzidas aos alunos naturalmente. 


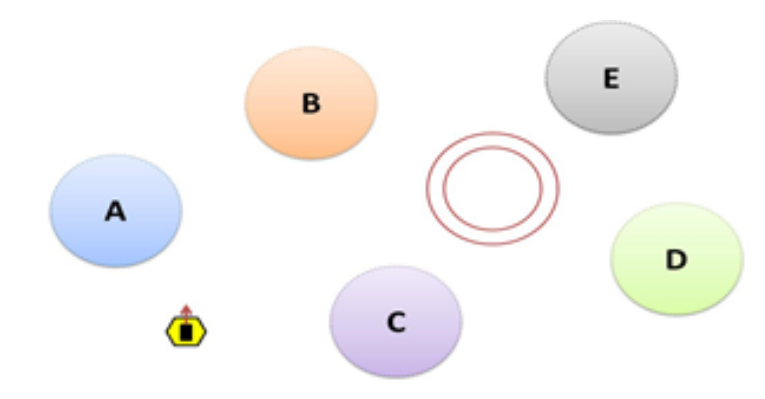

Figura 6. Atividade final do plano de aula exemplo.

Para finalizar o plano de aula, é proposta a atividade de avaliação a qual mescla todos os conceitos desenvolvidos nas seis atividades anteriores. Com isso, há um fechamento das atividades e o professor é capaz de identificar o que os alunos conseguiram compreender do tema e quais são as dificuldades existentes tendo por opção reaplicar ou não alguma das atividades desenvolvidas.

Com estas atividades, podemos perceber que os alunos participam atividade da construção de seu conhecimento. Assim, passam a fazer parte do ambiente de aprendizagem, são desafiados, compartilham experiências, projetam soluções, envolvem-se com o problema e na busca pela solução.

\section{Conclusões}

De modo geral, é possível perceber que o uso desta metodologia aproxima a relação estabelecida entre aluno e professor, rompendo barreiras que podem comprometer o processo de construção do conhecimento.

Ao utilizarmos esta metodologia na qual baseia-se na robótica educacional, a curva de aprendizagem dos alunos melhoram ao passo que os alunos conseguem aprender mais em menos tempo. Além disso, pelo fato da metodologia basear-se no construcionismo, a tecnologia empregada para mediar esta construção do conhecimento ou seja o robô, Curumim, convida o aluno a vivenciar a Realidade Virtual com o cerca, motivando-o o tornando-o mais participativo e ativo. Neste processo, tanto aluno quanto professor são beneficiados.

Entendemos que a formação do professor é um processo inacabado e que, por esta razão, necessita de constante movimentos que proporcionem esta formação. Acreditamos que, ao propor este material e concomitantemente a isso, oferecer o curso de capacitação e o apoio online, o professor sente-se, assim como o aluno, motivado e capaz de se inserir neste novo conceito de escola e educação que faz parte da nossa realidade atual. Para que haja ensino de qualidade, alunos e professores devem se sentir motivados e preparados. Diante das inúmeras tecnologias presentes no país atualmente e a educação se perdendo em meio a elas, esta proposta reafirma a necessidade de adaptarmos materiais para o ensino.

\section{Referências}


CURCIO, C. P. de C. (2008) "Proposta de método de robótica educacional de baixo custo", Dissertação (Mestrado) - Instituto de Tecnologia para o Desenvolvimento - LACTEC, Programa de Pós- Graduação em Desenvolvimento de Tecnologia.

FROTA, M. C. R.; BORGES, O. (2003) "Perfis de entendimento sobre o uso de tecnologias na Educação Matemática”. São Paulo. Editora UFMG.

GATTI, B. (1992) “Informação e Tecnologia”, In: Educadores para o século XXI: uma visão interdisciplinar. São Paulo. Editora Unesp.

KINZEN, I. M. G. et al (2007) "Kit de robótica educativa: desenvolvimento e aplicação metodológica”, In: Encontro da Escola Regional de Licenciatura em Computação II, Santa Cruz, p. 1 - 4 .

LARROSA, J. (2002) "Notas sobre a experiência e o saber de experiência", In: Revista Brasileira de Educação, n 19, p. 20 - 28.

NETTO, A. V.; MACHADO, L. S.; OLIVEIRA, M. C. F. (2002) "Realidade Virtual Definições, Dispositivos e Aplicações".

PAIS, L. C. (2002) "Educação escolas e as tecnologias da informática”, Belo Horizonte.

PAPERT, S. (1994) “A máquina das Crianças - Repensando a Escola na Era da Informática”. Porto Alegre. Editora Artes Médicas.

PAPERT, S. (2002) “A Máquina das Crianças”, Porto Alegre.

SAVIANI, D. (2009) "Formação de professores: Aspectos históricos e teóricos do problemas no contexto brasileiro", In: Revista Brasileira de Educação, n 40, p. $143-155$.

SILVA, A. R. S.; LIMA, C.P. (2007) “ Robótica na educação: reflexão sobre o uso de robôs no ensino fundamental público do RN”, In: Seminário de Pesquisa de CCSA, Natal, p. $30-36$. 